\title{
Professoras de biologia: história de vida, formação e contexto educacional brasileiro (1960-2010)
}

\author{
lara Mora Longhini \\ Universidade Federal de Uberlândia
}

\section{Resumo}

Este texto é resultado de uma pesquisa em que procuramos relacionar a formação de professoras de biologia de diferentes regiões do Brasil ao contexto educacional do país no período de 1960 a 2010, a partir de suas histórias de vida. Para tanto, este trabalho tem por base a descrição interpretativa e se utiliza da história de vida como procedimento investigativo, no campo das pesquisas qualitativas na área da educação. Os resultados revelam a estreita relação existente entre o contexto sócio-político-educacional e a formação docente, uma vez que é aquele que norteia as políticas de formação do profissional docente.

Palavras-chave: Professoras de biologia. Ensino de biologia. História de vida. Formação. 


\section{Biology teachers: life stories, education and the Brazilian educational context (1960-2010)}

This paper is the result of research in which we seek to correlate the education of female Biology teachers from different regions of Brazil with the educational context of the country in the period from 1960 to 2010, based on their life stories. Thus, this study is based on interpretive description and makes use of the life story as an investigative procedure in the field of qualitative research in the area of education. Results reveal the close relationship existing between the socio-politico-educational context and teacher education, since it is the former that directs the policies for the education of teaching professionals.

Keywords: Biology teachers. Biology teaching. Life story. Education.

\section{Profesoras de biología: historia de vida, formación y contexto educacional brasileño (1960-2010)}

Este texto es el resultado de una investigación, en la buscamos relacionar la formación de profesoras de Biología de diferentes regiones de Brasil al contexto educacional del país, durante el período comprendido entre 1960 y 2010, a partir de sus historias de vida. De ese modo, este trabajo toma por base la descripción interpretativa y se sirve de la historia de vida como procedimiento investigativo, en el campo de las investigaciones cualitativas en el área de educación. Los resultados revelan la estrecha relación existente entre el contexto socio-político-educacional y la formación docente, una vez que aquel nortea las políticas de formación del profesional docente.

Palavras-chave: Profesoras de biología. Enseñanza de biología. Historia de vida. Formación. 


\section{História de vida de professores}

Muitos estudos das histórias de vida, no campo educacional, centram-se na pessoa do professor, com ênfase nas subjetividades e identidades que as histórias comportam, como têm destacado Souza e Fornari (2008). Com a centralização dos estudos e práticas de formação na pessoa do professor, busca-se abordar a constituição do trabalho docente, levando em conta os diferentes aspectos de sua história (pessoal, profissional e organizacional). Percebe-se, então, uma tomada de consciência que nos permite reconhecer os saberes construídos pelos professores, no seu fazer pedagógico diário.

Os estudos sobre as histórias orais de vida enfocam a memória como fonte principal dos dados. Cada ator em cena é o próprio autor da sequência de fatos que compõe a construção do enredo a ser conhecido, a partir de suas lembranças.

Refletir sobre as nossas próprias práticas profissionais é uma forma de interpelar o espaço em que construímos nossa identidade, que se caracteriza como lugar de conflitos e de elaboração de modos de ser e estar na profissão. É a nossa prática que evidencia como nos sentimos e nos afirmamos professores.

No que se refere às pesquisas que focam as histórias de vida de professores, Goodson declara que

podem ajudar-nos a ver o indivíduo em relação com a história de seu tempo, permitindonos encarar a intersecção da história da vida com a história da sociedade, esclarecendo, assim, escolhas, contingências e opções com que se depara o indivíduo [...]. (Goodson, 1992, p. 75)

Segundo Oliveira (2006), a narrativa oral viabiliza conhecimentos que falam das imagens, dos saberes e fazeres, dos processos de identificação, das experimentações que se vão colocando na vida pessoal e profissional.

Por meio das histórias de vida contadas, oralmente, aproximamo-nos de imagens reconstruídas no presente, a partir de significados atribuídos às trajetórias vividas. É possível conhecer os processos de formação, os saberes dos professores, visitarmos as paisagens, os comportamentos, os tempos vividos por meio dos sentidos trazidos ao momento da construção da narrativa.

Cada participante dessa pesquisa pode reconstruir sua trajetória, possibilitandonos identificar os significados que atribuem aos saberes e práticas, aos modos de reconstrução de identidades profissionais de atores de diferentes localidades do Brasil, que escreveram e continuam escrevendo a história do ensino de biologia. 


\section{Ensino das ciências no contexto político-educacional brasileiro, no período de 1960 a 2010}

Ao nos reportarmos ao intervalo de tempo entre 1960 e 2010, é importante destacar que três leis regeram a educação neste período: a Lei de Diretrizes e Bases da Educação (LDB), Lei no 4.024, de 20 de dezembro de 1961, a Lei no 5.692, de 11 de agosto de 1971, e a Lei de Diretrizes e Bases da Educação Nacional promulgada em 20 de dezembro 1996, sob o no 9.394. Assim, neste item, fazemos o retrospecto histórico do ensino de biologia focando tais legislações.

Apesar de o foco do nosso trabalho ser o ensino de biologia, é preciso lembrar que em alguns momentos, ao longo da história, os componentes da biologia estão relacionados, de forma geral, com ensino de ciências físicas e biológicas, como aconteceu na Lei no 5.692/71. Assim, ao nos referirmos aos aspectos do ensino, usamos o termo área das ciências, englobando as ciências biológicas, as ciências naturais e/ou as ciências físicas e biológicas, que podem estar ou não desdobradas nas disciplinas biologia, química e física.

Segundo a Lei $n^{0}$ 4.024/61, a disciplina ciências tinha como propósito desenvolver o espírito crítico a partir do exercício do método científico. De acordo com aquela lei, como afirmam Rodrigues e Mendes Sobrinho (2008), o ensino de ciências foi introduzido no currículo do então ensino médio como condição para a formação do cidadão e para atender às necessidades do desenvolvimento tecnológico do País.

Santos e Mendes Sobrinho (2008) destacam que a LDB n0 4.024/61 estimulou a maior diversidade de livros, além de mudanças nas orientações epistemológicas relacionadas ao ensino de ciências, devido às influências dos projetos de renovação curricular desenvolvidos nos Estados Unidos e na Inglaterra, principalmente a partir de 1964.

Segundo diversos autores, entre eles Fracalanza (1992), Cazelli, Marandino, Studart (2003) e Chassot (2003), o grande impacto causado na sociedade americana pelo lançamento do Sputnik, em 1957, fez com que, na década de 1960 , novas abordagens fossem propostas para o ensino das ciências, com o propósito de minimizar o analfabetismo científico e tecnológico nos Estados Unidos da América.

Naquele país, seria constituída, no final da década de 1950, a instituição Biological Science Curriculum Studies (BSCS), cujo objetivo era o desenvolvimento de programas educacionais especificamente para a biologia. A partir do BSCS, o movimento internacional de melhoria do ensino de biologia foi dando origem a novos projetos em vários países.

No Brasil, uma importante alteração ocorrida no ensino de biologia, nas décadas de 1950 e 1960, foi a corporificação das modificações previstas em projetos de ensino, constituídos basicamente por livro texto para o aluno, livro guia para o professor e material de laboratório. 
No entanto, conforme afirma Krasilchik (1987), no período compreendido entre as décadas de 1950 e 1960, o ensino da área das ciências estimulava, basicamente, a passividade, e as modificações necessárias centravam-se na importância de se acrescentar o conhecimento científico às disciplinas escolares, além da incorporação dos métodos ativos. Nesse período, as mudanças curriculares preconizavam a substituição de métodos expositivos de ensino por métodos ativos, ou seja, que enfatizavam a importância da utilização do laboratório no oferecimento de uma formação científica de qualidade aos estudantes.

Como expressa Selles (2007, p. 5)

o movimento de renovação curricular de ciências assentou-se na convicção de que o ensino no laboratório possibilitaria aos alunos internalizarem o método da pesquisa científica e, por conseguinte, melhoraria o ensino de ciências. Nos BSCS uma das principais inovações centrava-se na defesa do ensino de biologia experimental como uma forma de romper com práticas que atrelavam esta disciplina escolar às tradições de memorização, passividade dos alunos e excesso de conteúdos desatualizados.

A partir de meados da década de 1960, segundo Nascimento, Fernandes e Mendonça (2010), importantes temas relacionados às descobertas científicas passaram a fazer parte do ensino das ciências. Ele passou a ter como objetivos essenciais levar os alunos à aquisição de conhecimentos científicos, atualizados e representativos do desenvolvimento científico e tecnológico e vivenciar os processos de investigação científica.

Na década de 1970, segundo convalidam Rodrigues e Mendes Sobrinho (2008), o ensino das ciências foi marcado pelo uso da experimentação com a participação do aluno por meio do método da redescoberta. A existência de aulas práticas era considerada meta importante a ser atingida, como parte do processo de aprimoramento do ensino das ciências, pois fazia o aluno "pesquisar", participando do processo de redescoberta.

Krasilchik (1996) informa que, a partir da Lei n 5.692/71, o ensino das ciências passou a ser voltado para a preparação de um corpo qualificado de trabalhadores, situação esta que acarretou o atravancamento de disciplinas de cunho científico nos currículos escolares, em prol daquelas de cunho profissionalizante. 0 núcleo das ciências passou a ter, no $2^{\circ} \mathrm{grau}$, as disciplinas ciências físicas e biológicas e matemática.

Ao longo dos anos 70,0 ensino das ciências, tanto no $1^{\circ}$ quanto no $2^{\circ}$ grau, esteve fortemente influenciado pela concepção empirista de ciência, segundo a qual as teorias são originadas a partir da experimentação, de observações seguras e da objetividade e neutralidade dos cientistas. 0 objetivo principal das aulas referentes às ciências era a vivência do método científico pelos alunos.

Nesse período, houve grande preocupação em relação ao ensino e à aprendizagem dos conteúdos científicos, bem como com o desenvolvimento de 
habilidades científicas pelos estudantes, visto que o país necessitava enfrentar a "guerra tecnológica" travada pelas grandes potências econômicas. Nesse período, como afirma Krasilchik (1996), as propostas de melhoria do ensino das ciências apareciam com títulos impactantes como, por exemplo, "educação em ciência para a cidadania" e "tecnologia e sociedade", tendo em vista a contribuição com o desenvolvimento do País.

Segundo Krasilchik (1996), em meados dos anos 80, as propostas para 0 ensino das ciências passaram a reconhecer que as explicações científicas eram impregnadas de ideologias, valores e crenças, pois eram construídas a partir do pensamento e da ação dos cientistas durante os processos de investigação.

As propostas educativas fundamentadas pelas teorias cognitivistas, como explicam Nascimento, Fernandes e Mendonça (2010), reiteravam a necessidade de os estudantes não serem receptores passivos de informações ou meros aprendizes, pois deveriam saber usar, questionar, confrontar e reconstruir os conhecimentos científicos.

Ainda na década de 1980, parte significativa das propostas educativas fundamentava-se no pressuposto da "didática da resolução de problemas", tendo em vista possibilitar aos estudantes a vivência de processos de investigação científica e a formação de habilidades cognitivas e sociais.

Em 1983, a Coordenação de Aperfeiçoamento de Pessoal de Nível Superior (Capes), como parte do Programa de Apoio ao Desenvolvimento Científico e Tecnológico (PADCT), criou um novo projeto para a melhoria do ensino das ciências e matemática, passando a constituir o Subprograma Educacional para a Ciência (SPEC), cujos objetivos foram, entre outros, a melhoria do ensino das ciências e matemática, a melhoria na formação de professores e a implementação de novas metodologias. Por meio desse programa, algumas universidades, em parceria com as escolas de ensino fundamental e médio, desenvolveram cursos de formação continuada para professores dessas áreas. Tal programa possibilitou a construção de laboratórios de ensino de ciências, nas instituições de ensino superior.

Segundo Rodrigues e Mendes Sobrinho (2008), nos anos da década de 1980, houve o abandono dos grandes projetos (dos kits de ciências, dos laboratórios, etc.) realizados em sala de aula e surgiu um movimento de pequenos projetos, centrados na escola e no professor. Iniciou-se, no Brasil, a fase de investigações sobre os "conceitos espontâneos" dos alunos, com a ideia de ensinar à criança a partir do que ela já trazia para a sala de aula, das explicações que ela tivesse para os fenômenos naturais.

Segundo Fracalanza (1992), na década de 1980, foram priorizadas novas diretrizes, pautadas no movimento Ciência, Tecnologia e Sociedade, a educação ambiental e a valorização dos aspectos cognitivos da cultura e do cotidiano do aluno.

De meados dos anos 80 até quase o fim da década de 1990, foi um período marcado pelas contestações às metodologias ativas e a incorporação do discurso 
da formação do cidadão crítico, consciente e participativo.

Em 1996, foi promulgada uma nova LDB, que vigora até os dias de hoje. Na lei no 9.394/96, a educação é dividida em básica e ensino superior. Fazem parte da educação básica a educação infantil, o ensino fundamental (dividido em I e II) e o ensino médio.

No que se refere às Diretrizes Curriculares Nacionais para o Ensino Médio (DCNEM), lançadas em 1998, em seu art. $10^{\circ}$ há o estabelecimento da base nacional comum dos currículos do ensino médio, organizada em três áreas de conhecimento, entre elas a de ciências da natureza, matemática e suas tecnologias, com uma lista de objetivos que visam permitir a constituição de habilidades e competências ao educando.

Os Parâmetros Curriculares Nacionais para o Ensino Médio (PCNEM), publicados em 1999, detalham os conhecimentos da cada uma das ciências da natureza e, quanto à biologia, apregoa que seu aprendizado

[...] deve permitir a compreensão da natureza viva e dos limites dos diferentes sistemas explicativos, a contraposição entre os mesmos e a compreensão de que a ciência não tem respostas definitivas para tudo, sendo uma de suas características a possibilidade de ser questionada e de se transformar. Deve permitir, ainda, a compreensão de que os modelos na ciência servem para explicar tanto aquilo que podemos observar diretamente, como também aquilo que só podemos inferir; que tais modelos são produtos da mente humana e não a própria natureza, construções mentais que procuram sempre manter a realidade observada como critério de legitimação. (Brasil, 1999, p. 14)

[...] Mais do que fornecer informações, é fundamental que o ensino de Biologia se volte ao desenvolvimento de competências que permitam ao aluno lidar com as informações, compreendê-las, elaborá-las, refutá-las, quando for o caso, enfim, compreender o mundo e nele agir com autonomia, fazendo uso dos conhecimentos adquiridos da Biologia e da tecnologia. (Brasil, 1999, p.19)

Os PCN+, publicados em 2002, propostos como orientações complementares aos PCNEM, apresentaram um diálogo direto com os professores e os educadores, diminuindo a distância entre a proposição das ideias e sua execução. Desta forma, esses parâmetros sugerem seis temas estruturadores para o ensino de biologia, além de apresentar ainda algumas estratégias para o ensino desse componente curricular.

De acordo com os PCN+, o ensino de biologia deveria pautar-se pela alfabetização científica. Ressalta que esse conceito implica três dimensões: a aquisição de um vocabulário básico de conceitos científicos, a compreensão da natureza do método científico e a compreensão sobre o impacto da ciência e da tecnologia sobre os indivíduos e a sociedade.

Atualmente, esse movimento de educação científica ou alfabetização científica objetiva a formação de cidadãos capazes de fazer opções conscientes e de estabelecer relações claras entre ciência, tecnologia, sociedade e ambiente. 
0 que se pode destacar deste breve retrospecto histórico é que o papel que se requisita ao professor de biologia desempenhar passou por várias modificações no período em questão, ante as diferentes tendências pelas quais a educação também passou. A identidade docente e, por consequência, suas práticas profissionais foram construídas neste contexto de permanentes mudanças e sobre ele exerceu também influências.

\section{A realização metodológica do trabalho}

0 objetivo deste texto é explicitar como se relacionam as histórias de vida de professoras de biologia e sua formação aos diferentes contextos políticoeducacionais enfrentados por esta área do saber, no período de 1960 a 2010.

Para o registro das narrativas orais, referenciamo-nos, primeiramente, na pesquisa qualitativa, tal como delineada por Bogdan e Biklen (1991), e nos procedimentos da história oral, como descrito por Meihy e Holanda (2007).

Apesar de o trabalho de tese ter-se utilizado dos procedimentos metodológicos da história de vida e de as professoras terem sido identificadas nominalmente, para a publicização de seus resultados trataremos nossas colaboradoras por professoras $1,2,3,4,5,6,7,8$ e 9 . Vale destacar que todas as nossas colaboradoras são do sexo feminino, embora isto não tenha sido intencional.

As colaboradoras foram escolhidas de acordo com os seguintes critérios: 1) terem vivenciado a prática como professoras de biologia, na educação básica, no período de 1960 até $2010 ; 2$ ) terem, na memória, a história dessa disciplina curricular; 3) viverem nas diferentes regiões geográficas do País; e 4) serem de diferentes gerações, formações e atuações.

Os registros das professoras foram feitos utilizando-se de entrevistas, com base nos dados de seu percurso de vida pessoal e sua formação, tanto na educação básica quanto no ensino superior, incluindo a formação inicial e a continuada.

Após a realização das entrevistas, transcrevemos literalmenteasfalas eenviamos as transcrições para as colaboradoras, para conferências e esclarecimentos, em caso de dúvidas. Em seguida, realizamos a textualização da entrevista, retirando as perguntas, procurando dar coerência ao texto e adaptando-o às normas cultas da língua portuguesa. Os textos foram novamente encaminhados para as entrevistadas para que elas conferissem e fizessem as alterações consideradas pertinentes, a fim de autorizar a utilização das informações. 


\section{0 que a pesquisa revelou?}

O que ouvimos das participantes desta pesquisa, parte do trabalho de tese, são recortes feitos a partir de suas experiências e lembranças, via memória, mas de fundamental importância para compreender os acontecimentos que marcaram suas trajetórias profissional e pessoal. Nessa perspectiva, o sentido que atribuímos ao termo experiência aproxima-se do proposto por Larrosa (2002, p. 21), ou seja, "experiência é o que nos passa, o que nos acontece, o que nos toca".

A seguir, apresentamos um quadro síntese com os dados gerais das nossas colaboradoras.

Quadro 1 - Dados gerais sobre as professoras entrevistadas

\begin{tabular}{|c|c|c|c|c|c|c|c|c|c|}
\hline & 1 & 2 & 3 & 4 & 5 & 6 & 7 & 8 & 9 \\
\hline $\begin{array}{c}\text { Ano de } \\
\text { nascimento }\end{array}$ & 1946 & 1956 & 1960 & 1966 & 1956 & 1937 & 1942 & 1946 & 1966 \\
\hline $\begin{array}{l}\text { Cidade } \\
\text { onde } \\
\text { nasceu }\end{array}$ & $\begin{array}{l}\text { Santa } \\
\text { Helena } \\
\text { de } \\
\text { Goiás/GO }\end{array}$ & $\begin{array}{l}\text { Rio de } \\
\text { Janeiro/ } \\
\text { RJ }\end{array}$ & $\begin{array}{l}\text { Cuibá/ } \\
\text { MT }\end{array}$ & $\begin{array}{l}\text { Rio de } \\
\text { Janeiro/ } \\
\text { RJ }\end{array}$ & $\begin{array}{l}\text { Rio de } \\
\text { Janeiro/ } \\
\text { RJ }\end{array}$ & $\begin{array}{l}\text { Ribeirão } \\
\text { Preto/SP }\end{array}$ & $\begin{array}{l}\text { Altinópolis/ } \\
\text { SP }\end{array}$ & $\begin{array}{l}\text { Porto } \\
\text { Alegre } \\
\text { /RS }\end{array}$ & Belém/PA \\
\hline $\begin{array}{c}\text { Cidade } \\
\text { onde } \\
\text { trabalha }\end{array}$ & $\begin{array}{l}\text { Uberlândia/ } \\
\text { MG }\end{array}$ & $\begin{array}{l}\text { Brasília/ } \\
\text { DF }\end{array}$ & $\begin{array}{l}\text { Dourad } \\
\text { os/MS }\end{array}$ & $\begin{array}{l}\text { Rio de } \\
\text { Janeiro/ } \\
\text { RJ }\end{array}$ & $\begin{array}{l}\text { Rio de } \\
\text { Janeiro/ } \\
\text { RJ }\end{array}$ & $\begin{array}{l}\text { Campinas/ } \\
\mathrm{SP}\end{array}$ & $\begin{array}{l}\text { Ribeirão } \\
\text { Preto/SP }\end{array}$ & $\begin{array}{l}\text { Porto } \\
\text { Alegre } \\
\text { /RS }\end{array}$ & Belém/PA \\
\hline $\begin{array}{c}\text { Ano de } \\
\text { ingresso } \\
\text { na } \\
\text { graduação }\end{array}$ & 1970 & 1975 & 1982 & 1984 & 1976 & 1959 & 1962 & 1966 & 1983 \\
\hline $\begin{array}{c}\text { Ano de } \\
\text { ingresso } \\
\text { na } \\
\text { educação } \\
\text { básica } \\
\text { como } \\
\text { professor }\end{array}$ & 1969 & 1988 & 1989 & 1988 & 1981 & 1960 & 1966 & 1971 & 1986 \\
\hline $\begin{array}{c}\text { Ano de } \\
\text { ingresso } \\
\text { como } \\
\text { docente no } \\
\text { ensino } \\
\text { superior }\end{array}$ & 1983 & Não & 2005 & 1997 & Não & 1986 & 1968 & 1996 & 1992 \\
\hline $\begin{array}{l}\text { Local onde } \\
\text { cursou o } \\
\text { doutorado }\end{array}$ & USP/SP & Não & $\begin{array}{l}\text { UNIMEP } \\
\text { /SP }\end{array}$ & UFRJ/RJ & UFRJ/RJ & $\begin{array}{l}\text { UNICAMPI } \\
\text { SP }\end{array}$ & USP & $\begin{array}{l}\text { UFSC/ } \\
\text { SC }\end{array}$ & $\begin{array}{l}\text { UNICAMP } \\
\text { /SP }\end{array}$ \\
\hline
\end{tabular}

Fonte: Entrevistas da pesquisa.

Com relação às categorias de análise, focamos três delas: al as docentes e sua escolarização básica; b) a formação inicial das professoras de biologia, abordando a currículo de biologia e sua diversificação, e a dicotomia ensino/ pesquisa e a opção pela docência; e cl a formação continuada das docentes de biologia. 


\section{As docentes e sua escolarização básica}

0 quadro I evidencia que algumas professoras realizaram a escolarização básica', mesmo que de forma não completa, em um período que antecedeu a promulgação da LDB n0 4.024, de 1961 (1, 6, 7 e 8); outras realizaram seus estudos parcialmente no contexto desta lei e também no da LDB n0 5.692 de 1971 (2, 3 e 5), e outras foram escolarizadas estritamente no contexto da Lei de 1971, como é o caso das professoras 4 e 9. Tal fato nos explicita o quanto e de que forma cada uma das colaboradoras estava inserida em contextos sócio-político-educacionais diferentes.

Considerando que todas as nossas colaboradoras são do sexo feminino, vale destacar que a profissão de professora, historicamente, já foi encarada por muitas mulheres como a única ou talvez a mais viável para se conciliar com as tarefas exigidas para esse sexo. Segundo Fontana (2000), inicialmente a preocupação com a feminização do magistério recebeu tratamento estatístico e constatativo da presença da mulher na hierarquia e funcionamento dos sistemas de ensino, explicado a partir de uma perspectiva mais ampla da divisão sexual do trabalho nas sociedades capitalistas.

A ausência de diferenciação entre a profissional docente e a mulher auxiliou por muito tempo a resistência às transformações do papel da mulher na educação, bem como no mercado de trabalho.

No que concerne ao local de realização desse nível de escolarização em instituições públicas ou privadas, as professoras 6 e 7 asseguram que a escola pública não era para todos, era elitizada, e estudar em uma dessas instituições era considerado um privilégio, principalmente com relação ao colegial, quando se deveria optar entre fazer o científico, o clássico ou o normal. Outro fato lembrado pelas professoras foi a exigência de realização do exame de admissão. Tal exame tinha caráter obrigatório para o ingresso no ginásio e havia, inclusive, cursos preparatórios para esse exame. Neste sentido, ele era uma evidência de que uma parcela significativa de alunos ficava sem o direito de continuidade de seus estudos na escola pública. Isto nos incita a pensar para quem a escola pública era destinada, ou seja, havia uma elitização bastante significativa do ensino, pois, apesar de ser pública, a escola não contemplava a todos. Isto ocorria também no colegial, atual ensino médio.

A opção pelo estudo em escola pública ou privada feita pela família de nossas colaboradoras foi rememorada pela professora 4:

1. Estamos entendendo por escolarização básica os atuais ensinos fundamental e médio (LDB n0 9.394/1996), que já foram chamados de primário, ginásio e colegial (LDB $n^{0}$ 4.024/1961) e de primeiro e segundo graus (Lei $n^{0} 5.692 / 19711$. 
Sou de uma família que valoriza muito o estudo. Éramos de classe média baixa, mas o dinheiro para o estudo, as coisas para o estudo eram fundamentais, eram o que mais importava. Era estudar, fazer inglês, escolher uma escola. Eu peguei a Lei 5.692 e, nesse contexto, os meus pais se preocupavam com as condições do ensino público, em como iríamos nos formar nesse período. É justamente o período que a classe média abandona a escola pública, e meus pais estavam vivendo esse momento. Então, a partir da $5^{a}$ série, colocaram-me em uma escola privada que era famosa na região. Eles se sacrificaram para que pudéssemos ter uma educação de qualidade, o que eles entendiam por uma educação de qualidade. (Professora 4)

Nesse depoimento fica evidente o quanto a escola pública foi perdendo prestígio para uma determinada camada da população. De outro modo, devemos registrar que a legislação vigente definia como prioridade a terminalidade dos estudos no nível médio de ensino, visando à diminuição pela procura da formação acadêmica junto às instituições de ensino superior.

\section{Formação inicial das professoras de biologia}

Aqui abordamos a formação das professoras sob a óptica do currículo de biologia e sua diversificação, e a dicotomia entre ensino/pesquisa e a opção pela docência.

\section{0 currículo de biologia e sua diversificação}

O curso de ciências biológicas tem sua origem na década de 1960, em substituição ao de história natural. Assim, em nosso trabalho, temos professoras que vivenciaram as duas experiências.

Para o curso de ciências biológicas, observamos uma diversidade curricular significativa, levando em conta a época em que as participantes da pesquisa cursaram a graduação. Em geral, a média de duração dos cursos foi quatro anos, denominados licenciatura plena?2.

Nos cursos de quatro anos, considerados de graduação plena, constatamos duas modalidades curriculares: uma considera um currículo mais integralizado, a outra modalidade é denominada pelas depoentes de " 3 mais 1 ".

0 modelo " 3 mais 1", vigente na época em que essas professoras se graduaram, estava amparado pela Lei no 5.540/68 (Reforma Universitária). Foi com base

2. Por um lado, temos depoimentos de cursos de quatro anos regulares, considerados licenciatura plena. Por outro lado, verificamos a existência de cursos de curta duração, também conhecidos como licenciatura curta. 
nessa lei que a estrutura curricular das faculdades sofreu fragmentação em departamentos; a matrícula dos alunos passou a ser por créditos e os cursos de licenciatura, em geral, ofereciam três anos de disciplinas chamadas específicas, e apenas no último ano eram trabalhadas as disciplinas pedagógicas.

Para os cursos de curta duração, tivemos a experiência vivida pela professora 1. Ela iniciou seu curso de biologia na modalidade licenciatura curta, cujo foco era formar o professor exclusivamente para lecionar.

Por meio dos depoimentos de nossas colaboradoras, observamos, também, a influência que o cotidiano exerce sobre o tempo de conclusão do curso de nível superior.

Constatamos uma grande diversidade de experiências vivenciadas pelas professoras. A dificuldade em estudar em curso noturno, a oportunidade, considerada positiva, de participar de atividades extra-acadêmicas com foco em discussões políticas e filosóficas e a ocorrência de greves foram destacadas pelas professoras como indicativo de como o contexto influenciou a duração do curso.

Pelos depoimentos, notamos sérias restrições, de parte significativa das docentes, ao processo de formação para a docência; elas salientaram, principalmente, o sentido do componente "estágio supervisionado". Verificamos, independentemente do período do curso, uma forte crítica a este componente curricular.

Segundo a professora 9, não houve necessidade de realizar estágio, pois já lecionava, assim o foco era estagiar em outros locais, atividade não cumprida por ela. Isto evidencia que o foco desse curso, realmente, não estava na formação docente, mas voltado para a formação do profissional da biologia, o biólogo.

Tais afirmações corroboram os paradigmas da "racionalidade técnica" (Schön, 1992) ou "aplicacionista" (Tardif, 2000), nos quais há uma dissociação entre a produção de conhecimentos, a formação e a prática. Os pesquisadores, dentro das universidades, geram conhecimentos que devem ser transmitidos nas disciplinas que compõem a base dos currículos escolares e, em seguida, devem ser aplicados na prática pedagógica dos professores. Essa prática é considerada completamente dissociada do conhecimento cientificamente produzido. É como se estes conhecimentos não fizessem parte do processo de formação do docente no nível superior.

Segundo algumas colaboradoras, o estágio é visto, às vezes, como algo menos importante, que pode, inclusive, não ser realizado, caso o futuro professor já tenha alguma experiência profissional anterior. Portanto, podemos inferir o quanto a realização do estágio era negligenciada nos cursos de formação docente, ou seja, os aspectos pedagógicos da formação nos cursos de graduação, mesmo na modalidade licenciatura, nem sempre foram entendidos como centrais em tais cursos.

Atualmente, as diretrizes curriculares dos diferentes cursos de graduação, publicadas na primeira década do século XXI, enfocam a formação pedagógica ao 
longo de todo o período dos cursos de licenciatura e destacam que o estágio deve ser iniciado a partir da segunda metade do curso em questão. Dessa forma, não é mais aceitável o estágio ocorrer somente no final do curso.

\section{A dicotomia ensino/pesquisa e a opção pela docência}

As professoras afirmaram que o curso superior de graduação não as havia preparado para darem aulas, mas, sim, para fazerem pesquisa.

Constatamos que nem sempre nossas colaboradoras desejaram exercer a docência, como é o caso das professoras 2,3 e 5 . Elas pretendiam ser pesquisadoras. Ser pesquisador, inicialmente, parece ao graduando uma atividade de status na profissão. A professora 2, por exemplo, embora não visse na docência perspectivas de sucesso financeiro, mudou de ideia ao vislumbrar a possibilidade de ingressar em um colégio militar, o que the permitiria acompanhar o marido, que era militar, e de esse colégio ser um local de trabalho que valorizava financeiramente o professor.

Assim, fica evidente o quanto a vida pessoal interfere ou permeia a carreira profissional, em especial no que se refere à situação econômica.

Entretanto, há entrevistadas que, por diferentes razões, sempre almejaram ser docentes. A professora 7 atribui esse desejo à sua personalidade e também à influência de alguns professores, tanto que optou por cursar história natural em São José do Rio Preto/SP, e não em Rio Claro/SP, pelo fato de no primeiro local o foco ser a formação docente. Assim, diante do exposto pela professora 7, podemos considerar que, já na década de 1960, possivelmente, não de forma explícita, mas no âmbito do senso comum, havia a dicotomia entre ensino e pesquisa.

A escolha pela profissão docente influenciada por professores tem sido estudada por diversos autores, entre eles Flores (2009). Segundo esta autora, essa influência está mais diretamente relacionada à pessoa do professor do que propriamente ao conteúdo e à forma como esse profissional ensina.

Outras razões destacadas na pesquisa de Flores (2009), além da possibilidade de emprego estável, era o desejo consciente de trabalhar com crianças e jovens. Tal motivação foi anunciada pela professora 8:

0 que me levou a optar por ensino é paixão. Minha paixão era por trabalhar com crianças do ensino fundamental. (Professora 8)

De forma geral, percebemos que as participantes desta pesquisa, mesmo tendo ingressado nos cursos de licenciatura em diferentes momentos - em alguns períodos, a profissão docente valorizada e reconhecida socialmente; em outros, já sofrendo sensível desvalorização, também fizeram suas escolhas conscientes 
do notório desprestígio dos cursos de licenciatura, cujo foco era a formação de professores, em contraposição aos cursos de bacharelado, que visavam à formação de pesquisadores em áreas específicas do conhecimento biológico.

Flores (2009), ao estudar os dilemas e entraves apresentados pelos professores no início da carreira, comenta que há uma separação significativa entre teoria e prática, além de uma preparação inadequada dos futuros professores para dar aulas. Sobre tal preparo inadequado para lecionar, os professores entrevistados por essa pesquisadora apontam os déficits na formação com relação à interação com os alunos, à gestão da aula e à aplicação dos conhecimentos aprendidos ao longo do curso.

Nos cursos de graduação em biologia, como atestam as professoras, a maioria dos componentes curriculares está voltada para o desenvolvimento de áreas de estudo específicas; o desenvolvimento desse currículo ocorre de modo fragmentado, sendo cada área tratada de forma isolada das demais.

Os conteúdos de fundamentação pedagógica, segundo Cicillini (2002), além de terem um espaço muito pequeno nos cursos de licenciatura em ciências biológicas, também são fragmentados. Além disso, praticamente não há interação entre os docentes das áreas de conteúdos específicos de biologia e os docentes da área pedagógica. É exatamente nesta ausente mas necessária articulação entre professores e pesquisadores das áreas específicas que insiste a colaboradora 7:

Eu sempre tive uma relação de construção com os biólogos, sempre gostei de trabalhar com os pesquisadores, diretamente da fonte; eles orientando os graduandos, alunos deles também, com os quais tinham compromisso na formação em ensino e pesquisa. (Professora 7)

A partir das nossas entrevistas, podemos asseverar, concordando com Schulman (1986), que, para formar professores, é necessária a mobilização não só do conhecimento dos conteúdos específicos, mas também dos pedagógicos e do conhecimento pedagógico do conteúdo, ou seja, tornar-se professor de biologia está além do domínio dos conhecimentos específicos desse ramo do saber.

\section{Formação continuada das docentes de biologia}

Todas as professoras colaboradoras de nossa pesquisa se especializaram em cursos de formação continuada, principalmente em algum conteúdo relacionado à educação, seja nas questões epistemológicas ou metodológicas, seja nas relacionadas à prática de ensino.

Algumas professoras realizaram cursos de pós-graduação lato sensu ou stricto sensu, cursos de capacitação docente, participação em atividades de pesquisa, a 
fim de discutirem e aperfeiçoarem sua formação.

Encontramos professoras que fizeram especialização lato sensu, caso das professoras 5 e 9, ambas na área de ensino. Para a professora 5, esse foi o momento de estudar um pouco sobre a concepção prévia dos alunos, e a monografia resultante dessa especialização foi um dos trabalhos que mais a satisfez no âmbito da academia.

É possível perceber que a especialização contribuiu para a formação e a melhoria das atividades docentes. Além disso, também podemos constatar a importância dos cursos que visavam à formação de professores, por meio da interação entre a universidade e a escola de educação básica, característicos de meados da década de 1980 e início dos anos 90 . Tais cursos enfocavam a abordagem sociointeracionista a partir de autores como Vygotsky, por exemplo.

A professora 2 também ressalta a relevância do curso de capacitação que frequentou em Salvador/BA.

Inclusive, muito material de um curso que eu frequentei em Salvador/BA, um curso fantástico de experimentos do ensino fundamental de $6^{\circ}$ ao $9^{\circ}$ ano. Aquele que eu fiz na década de 1990 levou muito assunto interessante para sala de aula. [...] Eles traziam os professores para lá, para eles serem multiplicadores do ensino. (Professora 2)

0 depoimento da professora 2, para além do contato intensivo com os pesquisadores e demais professores da educação básica, retrata o valor significativo atribuído aos experimentos (característica dos anos 60 e 70), em detrimento de outros aspectos, como, por exemplo, as relações entre Ciência, Tecnologia e Sociedade - CTS (enfaticamente abordadas na década de 1990), na melhoria da prática pedagógica de docentes de biologia

Com relação aos cursos de pós-graduação stricto sensu, com exceção da professora 7, todas cursaram mestrado. A professora 7 cursou direto o doutorado, opção possível em alguns programas de pós-graduação. À época de nossa entrevista, a professora 5 estava cursando o doutorado, e a professora 2 estava se preparando para ingressar nessa etapa de formação.

Algumas professoras relataram encontrar na pós-graduação a segurança para entender as questões metodológicas do ensino das ciências. Tal argumento explicita a importância da relação teoria e prática na formação docente, ou seja, não basta dominar a teoria e não ser capaz de contextualizá-la nas atividades pedagógicas, ou ter os saberes da experiência e ser incapaz de refletir sobre eles à luz das teorias da educação.

Também ficou explícito que nossas interlocutoras enveredaram-se pela área da educação em ensino de ciências ou de biologia; isso pode ser uma evidência do desejo e da crença dessas docentes em uma formação de melhor qualidade para a sua atuação profissional. Tal situação se revela em um universo de professoras que seguem para a área da educação, o que não necessariamente ocorre quando 
os biólogos professores ou professores de biologia cursam pós-graduação em áreas específicas do conhecimento biológico. Neste caso, há indícios de uma ênfase maior ainda no conteúdo (cada vez mais específico), em detrimento das questões metodológicas e/ou pedagógicas. Pelos depoimentos podemos inferir que, quando o professor de biologia ou o biólogo professor se encaminha pela área da educação, significativas mudanças podem ocorrer na sua prática docente, o que se manifesta como um desejo latente, ainda que na forma da constituição de um currículo oculto, por parte das nossas professoras. Essa realidade é explicitada pelas professoras 2, 3 e 9, por exemplo:

Considero que o mestrado mudou muito minha forma de pensar [...]. Fiquei muito mais preocupada com a forma como eu estava passando para o aluno do que eu era antes. (Professora 2)

A minha formação no mestrado e no doutorado me ajuda. [...]. 0 que me ajuda, me dá segurança, na minha prática profissional, é o domínio teórico que eu tenho da área, das questões da área. Isso me é muito claro. (Professora 3)

0 fato de eu ter entrado na pós-graduação, ter começado a desenvolver pesquisa na área de educação, possibilitou-me olhar a educação de vários ângulos. (Professora 9)

A professora 8 também salienta a forte influência que a pós-graduação exerceu em suas atividades pedagógicas na educação básica, uma vez que ela se empenhava em desenvolver com seus alunos a mesma forma de discussão que era realizada no âmbito da pós-graduação:

Era mais ou menos isso que eu fazia com meus alunos, só que em outro contexto, com alunos pequenos. Eu sempre gostei disso: do debate, da discussão, e vi que essa é uma área excelente para isso. (Professora 8)

As professoras 2, 3, 5 e 9 creditam ao convívio na pós-graduação a possibilidade de entenderem de forma mais sistemática, e não do senso comum, as questões pertinentes à área do ensino das ciências:

Eu entendo que, para isso, a docência, a pesquisa, a experiência, a troca são importantes, além do contato com os meus pares. Foram esses fatores que me possibilitaram ampliar meu repertório. (Professora 9)

A professora 1 assinala, em sua fala, a importância dos cursos de mestrado e doutorado na sua atividade com a pesquisa sobre ensino, além de promover a relação com a extensão: 
A vivência com a pesquisa no mestrado, no doutorado e, depois, como orientadora de monografias, TCCs, iniciação científica, mestrado e doutorado, instrumentalizou-me para realizar um ensino com pesquisa, sem dissociar as duas coisas, ainda possibilitando inter-relação com a extensão. (Professora 1)

A professora 9 acreditava à época que, se trabalhasse em outra perspectiva metodológica, os conceitos básicos por si só seriam aprendidos; uma postura característica de cursos de formação continuada, própria do final da década de 1970 e início dos anos 80, quando se acreditava que o domínio metodológico resolveria o problema dos professores no interior da sala de aula.

Assim, em relação à pós-graduação, as professoras a entendem como uma maneira de "aliviar as angústias profissionais", além de propiciar uma mudança significativa no entendimento das questões metodológicas na rotina da sala de aula.

Outra contribuição da pós-graduação é o ingresso na carreira de ensino superior. Algumas professoras destacaram ainda, a participação em projetos, atividades de extensão e cursos de pós-graduação, como foi o caso da professora 4, que evidencia seu estreito vínculo com o projeto denominado Fundão Biologia.

A professora 7 também frisa a importância de a universidade, por meio de seus pesquisadores, desenvolver atividades em parceria com os professores da educação básica. Neste sentido, ela defende, veementemente, a pertinência da parceria com os pesquisadores das áreas de conteúdos específicos da biologia e a necessidade de haver um grupo para se pensar a formação. Segundo ela, a atividade de ensino deve ser realizada como as de pesquisa, ou seja, é preciso ter plano e objetivo a serem avaliados, daí a relevância do apoio do pesquisador das áreas ditas específicas da biologia.

As falas das professoras 4 e 7 demonstram a indispensabilidade da parceria escola-universidade na formação continuada de professores, ênfase característica de meados da década de 1980 e início dos anos 90.

Assim, podemos verificar várias formas de contribuição positiva das professoras da educação básica com os pesquisadores, tanto dos conteúdos específicos da área de biologia quanto dos conteúdos pedagógicos, na universidade, local onde geralmente ocorrem os cursos de formação continuada.

Portanto, podemos verificar que a pós-graduação, na área de educação, é vivenciada por nossas colaboradoras como fundamental para suas práticas pedagógicas, uma vez que essa formação lhes permite encarar e discutir os problemas do ensino e da aprendizagem sob um novo foco, menos imediatista e com mais profundidade, preocupando-se de forma mais intensa com as questões metodológicas, e não necessariamente conteudistas. 


\section{Considerações finais}

Ao analisar a história de vida de cada uma dessas professoras, observamos que a sua formação sofreu influência da família, do contexto em que se formou profissionalmente, das condições econômicas, das oportunidades tidas, dos valores atribuídos a cada um dos desafios. Isso nos faz concordar com Thompson (1992) sobre as conexões existentes entre o sistema geral de estrutura econômica, de classe, de sexo e de idade, e o desenvolvimento do caráter pessoal. Também concordamos com Cunha (2002), quando esta afirma que o desenvolvimento pessoal e profissional são inseparáveis do dia a dia do professor e, principalmente, das atividades de sala de aula.

Assim, ao fazermos a síntese das histórias de vida dessas professoras de biologia e a relação com a sua formação e o contexto sócio-político-econômico no período de 1960 a 2010, consideramos que o que cada uma é e ensina reflete as diferentes formações, oportunidades e experiências que tiveram.

Ao conhecer as histórias dessas professoras, ficou evidente como o contexto social em que estiveram inseridas foi determinante para sua formação pessoal e profissional.

Após a realização desta pesquisa, podemos afirmar que, mesmo quando as pessoas são contemporâneas e compartilham a mesma atividade profissional, não é possível prever como o contexto sócio-político-econômico atingirá cada uma, pois a formação pessoal e profissional é embebida de sentidos e experiências que não são previsíveis, mas tecida a partir da trama, dos laços e abraços particulares de cada ser humano.

\section{Referências}

BOGDAN, Robert; BIKLEN, Sari Knopp. Investigação qualitativa em educação - uma introdução à teoria e aos métodos. Porto: Porto Editora, 1991.

BRASIL, Lei $n^{0}$ 4.024, de 20 de dezembro de 1961. Fixa diretrizes e bases da educação nacional. Brasília, DF, 1961.

. Reforma do Ensino Superior. Lei no 5.540, de 28 de novembro de 1968. Fixa normas de organização e funcionamento do ensino superior e sua articulação com a escola média, e dá outras providências. Brasília, DF, 1968.

. Lei n 0 5.692, de 11 de agosto de 1971. Fixa diretrizes e bases para o ensino de $1^{\circ}$ e $2^{\circ}$ graus, e dá outras providências. Brasília, DF, 1971.

BRASIL, Coletânea de Leis, Pareceres, Decretos-lei, Resoluções e Portarias. Ensino. Uberlândia, UFU, 1980, 1986, 1988.

Lei de Diretrizes e Bases da Educação Nacional. Lei no 9.394, de 20 de dezembro de 1996. Estabelece as diretrizes e bases da educação nacional. Brasília, 
DF, 1996.

Diretrizes Curriculares Nacionais para o Ensino Médio. Resolução CEB n. 3, de 26 de junho de 1998.

Ministério da Educação (MEC), Secretaria de Educação Média e Tecnológica (SEMTEC). Parâmetros Curriculares Nacionais para o Ensino Médio. Brasília: MEC/SEMTEC, 1999.

Ministério da Educação. Secretaria de Educação Média e Tecnológica.

$\mathrm{PCN}+$

Ensino Médio: orientações educacionais complementares aos Parâmetros Curriculares Nacionais. Ciências da Natureza, Matemática e suas Tecnologias. Brasília: MEC, SEMTEC, 2002.

CAZELLI, Sibele; MARANDINO, Martha; STUDART, Denise Coelho. Educação e Comunicação em Museus de Ciência: aspectos históricos, pesquisa e prática. In: GOUVÊA, Guaracira; MARANDINO, Martha; LEAL, Maria Cristina (Orgs.). Educação e Museu: a construção social do caráter educativo dos museus de ciência. Rio de Janeiro: Access, 2003. p.83-106.

CHASSOT, Ático. Alfabetização científica: questões e desafios para a educação. 3. ed. Ijuí: Ed. Unijuí, 2003. (Coleção educação em química).

CICILLINI, Graça Aparecida. Conhecimento científico e conhecimento escolar: aproximações e distanciamentos. In: CICILLINI, Graça Aparecida; NOGUEIRA, Sandra Vidal (Orgs.). Educação escolar: políticas, saberes e práticas pedagógicas. Uberlândia: EDUFU, 2002. p. 37-66.

CUNHA, Myrtes Dias da. Cotidiano e processo de formação de professores. In: CICILLINI, Graça Aparecida; NOGUEIRA, Sandra Vidal (Orgs.). Educação escolar: políticas, saberes e práticas pedagógicas. Uberlândia: EDUFU, 2002. p. 67-83.

FLORES, Maria Assunção. La investigación sobre los primeiros años de enseñanza: lecturas e implicaciones. In: MARCELO GARCÍA, Carlos. (Coord.) El profesorado principiante: inserción a la docencia. Barcelona: Octaedro, 2009. p. 59-98.

FONTANA, Roseli Cação. Como nos tornamos professoras? Belo Horizonte: Autêntica, 2000.

FRACALANZA, Hilário. O que sabemos sobre os livros didáticos para o ensino de Ciências no Brasil. 1992. (304p). Tese (Doutorado em Educação), Faculdade de Educação. Unicamp, Campinas/São Paulo, 1992.

GOODSON, Ivor. Dar voz ao professor: as histórias de vida do professor e o seu desenvolvimento profissional. In: NóVOA, António. (Org.) Vidas de professores. Porto: Porto Editora, 1992, p.63-78.

KRASILCHIK, Myriam. 0 professor e o currículo das ciências. São Paulo: EPU: Editora da Universidade de São Paulo, 1987.

. Prática de Ensino de Biologia. São Paulo: Editora Harbra Ltda, 1996.

LARROSA, Jorge. Notas sobre a experiência e o saber de experiência. Tradução: João Wanderley Geraldi. Revista Brasileira de Educação. n. 19, p.20-29. jan/fev/ mar/abr 2002. 
MEIHY, José Carlos Sebe Bom; HOLANDA, Fabíola. História oral: como fazer, como pensar. São Paulo: Contexto, 2007.

NASCIMENTO, Fabrício; FERNANDES, Hylio Laganá; MENDONÇA, Viviane Melo de. $O$ ensino de ciências no Brasil: história, formação de professores e desafios atuais. Revista HISTEDBR On-line, Campinas, n.39, p.225-249, set.2010. Disponível em <http://www.histedbr.fae.unicamp.br/revista/edicoes/39/index.html>. Acesso em 15 de set. de 2011.

OLIVEIRA, Valeska Fortes de. Narrativas e saberes docentes. In: . (Org.) Narrativas e saberes docentes. Ijuí: Ed. Unijuí, 2006. p. 169-190.

RODRIGUES, Maria de Lourdes Bandeira; MENDES SOBRINHO, José Augusto de Carvalho. Aspectos históricos do ensino de ciências naturais de $5^{\mathrm{a}}$ a $8^{\mathrm{a}}$ série do ensino fundamental. In: MENDES SOBRINHO, José Augusto de Carvalho. (Org.) Práticas Pedagógicas em ciências naturais: abordagens na escola fundamental. Teresina: EDUFPI, 2008. p. 61-102.

SANTOS, Ângela Regina dos Reis; MENDES SOBRINHO, José Augusto de Carvalho. 0 ensino de ciências naturais nas séries iniciais: tendências atuais. In: MENDES SOBRINHO, José Augusto de Carvalho. (Org.) Práticas Pedagógicas em Ciências Naturais: abordagens na escola fundamental. Teresina: EDUFPI, 2008. p. 27-60. SCHÖN, Donald. Formar professores como profissionais reflexivos. In: NÓVOA, António (org.) Os professores e a sua formação. Lisboa: Dom Quixote, 1992. p.7791.

SELLES, Sandra Escovedo. A produção dos BSCS: livros didáticos e história da disciplina escolar Biologia. In: Simpósio Internacional "Livro Didático-Educação e História”, 2007, São Paulo. Anais do Simpósio Internacional, São Paulo: USP, 2007. v. 1. p. 1-17.

SHULMAN, Lee. Those who understand: knowledge growth in teaching. Educational Researcher, 15 (2), 1986. p. 4-14.

SOUZA, Elizeu Clementino; FORNARI, Liege Maria Sitja. Memória, (auto)biografia e formação. In: VEIGA, Ilma Passos Alencastro; D’ÁVILA, Cristina. (Orgs.) Profissão docente: novos sentidos, novas perspectivas. Campinas, SP: Papirus, 2008. p. 109134. - (Coleção Magistério: Formação e Trabalho Pedagógico).

TARDIF, Maurice. Saberes profissionais dos professores e conhecimentos universitários: elementos para uma epistemologia da prática profissional dos professores e suas consequências em relação à formação para o magistério. Revista Brasileira de Educação. São Paulo, ANPEd, n.13, p. 5-24, jan.fev.mar.abril de 2000.

THOMPSON, Paul. A voz do passado: história oral. Rio de Janeiro: Paz e Terra, 1992.

Recebido em julho de 2012

Aprovado em setembro 2012 
lara Mora Longhini é doutora em Educação pela Universidade Federal de Uberlândia e Professora Adjunta da Faculdade de Educação da Universidade Federal de Uberlândia. Email: iaramorađayahoo.com.br ou iarađafaced.ufu.br 